\title{
What causes cooling water temperature gradients in a forested stream reach?
}

\author{
G. Garner ${ }^{1}$, I. A. Malcolm ${ }^{2}$, J. P. Sadler ${ }^{1}$, and D. M. Hannah ${ }^{1}$ \\ ${ }^{1}$ School of Geography, Earth and Environmental Sciences, University of Birmingham, Edgbaston, Birmingham, B15 2TT, UK \\ ${ }^{2}$ Marine Scotland Science, Freshwater Laboratory, Faskally, Pitlochry, Perthshire, PH16 5LB, UK \\ Correspondence to: G. Garner (g.garner@bham.ac.uk)
}

Received: 21 May 2014 - Published in Hydrol. Earth Syst. Sci. Discuss.: 17 June 2014

Revised: 12 November 2014 - Accepted: 21 November 2014 - Published: 20 December 2014

\begin{abstract}
Previous studies have suggested that shading by riparian vegetation may reduce maximum water temperatures and provide refugia for temperature-sensitive aquatic organisms. Longitudinal cooling gradients have been observed during the daytime for stream reaches shaded by coniferous trees downstream of clear cuts or deciduous woodland downstream of open moorland. However, little is known about the energy exchange processes that drive such gradients, especially in semi-natural woodland contexts without confounding cool groundwater inflows. To address this gap, this study quantified and modelled variability in stream temperature and heat fluxes along an upland reach of the Girnock Burn (a tributary of the Aberdeenshire Dee, Scotland) where riparian land use transitions from open moorland to semi-natural, predominantly deciduous woodland. Observations were made along a $1050 \mathrm{~m}$ reach using a spatially distributed network of 10 water temperature data loggers, 3 automatic weather stations and 211 hemispherical photographs that were used to estimate incoming solar radiation. These data parameterised a high-resolution energy flux model incorporating flow routing, which predicted spatio-temporal variability in stream temperature. Variability in stream temperature was controlled largely by energy fluxes at the water-columnatmosphere interface. Net energy gains occurred along the reach, predominantly during daylight hours, and heat exchange across the bed-water-column interface accounted for $<1 \%$ of the net energy budget. For periods when daytime net radiation gains were high (under clear skies), differences between water temperature observations increased in the streamwise direction; a maximum instantaneous difference of $2.5^{\circ} \mathrm{C}$ was observed between the upstream reach boundary and $1050 \mathrm{~m}$ downstream. Furthermore, daily maximum water
\end{abstract}

temperature at $1050 \mathrm{~m}$ downstream was $\leq 1{ }^{\circ} \mathrm{C}$ cooler than at the upstream reach boundary and lagged by $>1 \mathrm{~h}$. Temperature gradients were not generated by cooling of stream water but rather by a combination of reduced rates of heating in the woodland reach and advection of cooler (overnight and early morning) water from the upstream moorland catchment. Longitudinal thermal gradients were indistinct at night and on days when net radiation gains were low (under overcast skies), thus when changes in net energy gains or losses did not vary significantly in space and time, and heat advected into the reach was reasonably consistent. The findings of the study and the modelling approach employed are useful tools for assessing optimal planting strategies for mitigating against ecologically damaging stream temperature maxima.

\section{Introduction}

River temperature dynamics are of increasing interest to the scientific community, environment managers and regulators (Hannah et al., 2008), given climate change predictions (e.g. van Vliet et al., 2011; Beechie et al., 2013) and associated consequences for water temperature and, thereby, aquatic ecosystems (Poole and Berman, 2001; Caissie, 2006; Webb et al., 2008; Wilby et al., 2010; Leach et al., 2012). Numerous studies have demonstrated that the presence of riparian woodland can decrease diurnal variability and mean and maximum stream temperatures (e.g. Malcolm et al., 2008; Brown et al., 2010; Roth et al., 2010; Imholt et al., 2012; Garner et al., 2014a) or, conversely, that forest removal results in temperature increases (e.g. Macdonald et al., 2003; Rutherford et al., 2004; Danehy et al., 2005; Moore et al., 2005; 
Gomi et al., 2006). Consequently, there is substantial interest from researchers and stream managers in the potential of riparian vegetation to mitigate against climate change impacts (e.g. The River Dee Trust; Upper Dee riparian scheme, The River Dee Trust, 2011), especially in relation to thermal maxima.

Several studies have documented daytime cooling gradients (instantaneous decreases in downstream temperature) under forest canopies located downstream of open (no trees) land use, although the magnitude of reported cooling effects varied between studies (e.g. Brown et al., 1971; Rutherford et al., 1997; McGurck, 1989; Keith et al., 1998; Zwieniecki and Newton, 1999; Torgerson et al., 1999; Story et al., 2003; Westhoff et al., 2011). For example, McGurck (1989), Keith et al. (1998) and Story et al. (2003) observed gradients of between 4.0 and $9.2^{\circ} \mathrm{C} \mathrm{km}^{-1}$. Little is known about the energy exchange processes that generate this apparent cooling effect (Story et al., 2003). Studies by Brown et al. (1971) and Story et al. (2003) observed net energy gains to the water column measured predominantly across the air-water-column interface. The presence of net energy gains led both Brown et al. (1971) and Story et al. (2003) to attribute the generation of cooling gradients to groundwater inputs that were thought to be underestimated by unrepresentative energy exchange measurements made at a single point within the reach (e.g. Brown et al., 1971; Story et al., 2003; Moore et al., 2005; Leach and Moore, 2011; Garner et al., 2014a). Cooling gradients have also been observed in forested reaches downstream of open land use in which groundwater inputs are considered to be minimal (e.g. Malcolm et al., 2004; Imholt et al., 2010, 2012). However, an explicit conceptualisation of the processes driving observed patterns of cooling in forested reaches without groundwater inputs is lacking; this is essential if stream managers are to plan future riparian planting strategies that maximise benefits at minimal cost.

This study aims to quantify and model spatio-temporal variability in stream water temperature and heat fluxes for an upland reach of the Girnock Burn (a tributary of the Aberdeenshire Dee, Scotland) where riparian land use transitions from open moorland to semi-natural forest and in which stream temperature variability is driven largely by energy fluxes at the water-column-atmosphere interface (i.e. not confounded by groundwater inflow). The specific objectives are

1. to quantify the magnitude of instantaneous longitudinal water temperature gradients within the reach and identify the meteorological conditions under which the strongest and weakest gradients occur;

2. to explore the effect of changing riparian vegetation density on heat fluxes within the reach;

3. to understand, using a simple flow routing model in conjunction with a Lagrangian water temperature model, how water temperature changes as it travels through the forested reach and to attribute this to underlying processes.

\section{Study area}

A $1050 \mathrm{~m}$ study reach with no tributary inputs was established within Glen Girnock, an upland basin that drains into the Aberdeenshire Dee, northeast Scotland. Upstream of the reach $\left(\sim 24 \mathrm{~km}^{2}\right)$, land use is dominated by heather (Calluna) moorland. Within the reach, land use transitions from open moorland to semi-natural forest composed of birch $(B e-$ tula), Scots pine (Pinus), alder (Alnus) and willow (Salix) (Imholt et al., 2012).

Full details of the Girnock catchment characteristics are found in Tetzlaff et al. (2007). In brief, soils are composed primarily of peaty podsols with a lesser coverage of peaty gleys. Granite at higher elevations and schists at lower elevations dominate the geology, both of which have relatively impermeable aquifer properties (Tetzlaff et al., 2007). The riverbed in the study reach is composed primarily of cobble and boulder, with smaller patches of localised gravel accumulation. Previous work in the catchment suggests highly heterogeneous but spatially constrained groundwater discharge, with no significant groundwater inputs within the study reach (Malcolm et al., 2005). Thus in the absence of major groundwater inflow, heat exchange within the reach is dominated by fluxes at the water-column-atmosphere interface. The Girnock Burn flows in a mainly northerly direction and so experiences no significant changes in aspect that may influence solar-radiation receipt through topographic or bank shading (Fig. 1). Maximum and minimum elevations of the reach are 280 and $255 \mathrm{~m}$ respectively (Fig. 1). Mean wetted width was $9.5 \mathrm{~m}$ during the study period.

\section{Methods}

\subsection{Experimental design}

Ten water temperature loggers were deployed throughout a $1050 \mathrm{~m}$ reach of the Girnock where riparian land use transitions from open moorland to semi-natural forest (Fig. 1) and in which previous studies have identified measurable changes in stream temperature (e.g. Malcolm et al., 2004, 2008; Imholt et al., 2010, 2012). Three automatic weather stations (AWSs) were deployed along the reach to estimate spatiotemporal variability in energy fluxes: one in open moorland $\left(\mathrm{AWS}_{\mathrm{open}}\right)$ and two in semi-natural forest (AWS $\mathrm{AUS}$ followed

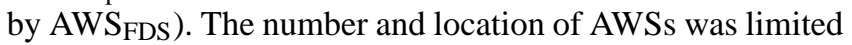
by logistical and financial constraints. However, 211 hemispherical photographs were taken at $5 \mathrm{~m}$ intervals along the reach so that solar radiation measured at the open-site AWS could be re-scaled to estimate radiative fluxes at a higher spatial resolution. For locations where hemispherical images were taken, turbulent (i.e. latent and sensible heat) and bed 

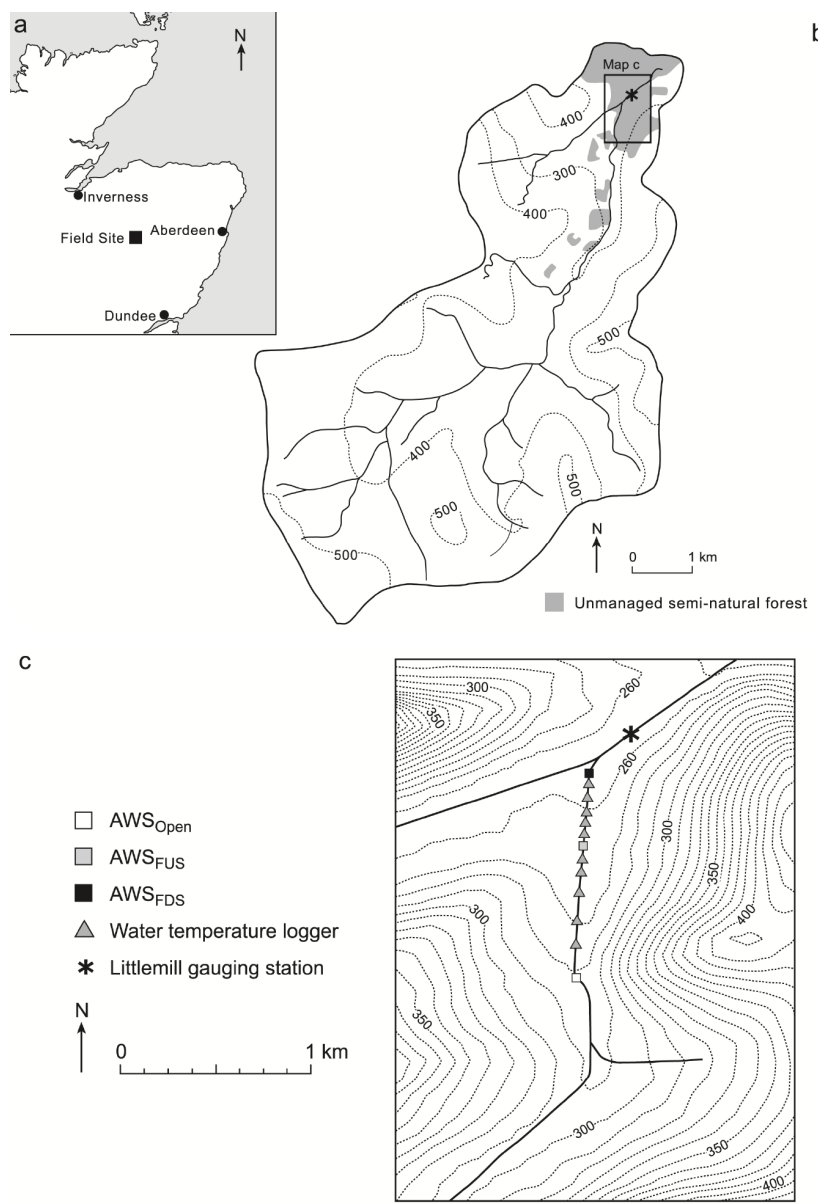

Figure 1. (a) Location map of the Girnock, (b) Girnock catchment and (c) locations of field data collection.

heat fluxes were estimated by linearly interpolating between values at the two nearest AWSs. High-resolution information on energy fluxes and stream temperature was combined with a flow routing model to provide a process-based understanding of spatio-temporal variability in stream temperature.

\subsection{Data collection}

Field data were collected between October 2011 and July 2013. A 7-day period (1 to 7 July 2013) characterised by high air temperatures (i.e. $>$ average air temperatures for this week in the preceding 10 years) and extremely low flows (i.e. $<$ average minimum flows for this week in the preceding 10 years) was chosen to meet the aims of the study (Fig. 2). High energy gains occurred on 6 days and relatively low energy gains occurred on 1 day. These data allowed the assessment of (1) potential mitigation of high temperatures by semi-natural forest under a "worst case scenario" of high energy gains and low flows and (2) the influence of contrasting prevailing meteorological conditions on longitudinal water temperature patterns.

\subsubsection{Stream temperature measurements}

Stream temperature measurements were made at $15 \mathrm{~min}$ intervals across a spatially distributed network of 10 water temperature TinyTag Aquatic 2 data loggers (manufacturerstated accuracy of $\pm 0.5^{\circ} \mathrm{C}$ ) and 3 Campbell 107 thermistors (manufacturer-stated accuracy $\pm 0.1^{\circ} \mathrm{C}$ ) connected to AWSs at 0 (AWS Open $\left._{\text {O }}\right), 190,315,460,565,630,685$ (AWS FUS ), 760, 815, 865, 9401015 and 1050 (AWS FDS m downstream of the upstream reach boundary (i.e. AWS $\mathrm{Apen}_{\text {) }}$ (Fig. 1). The sensors were cross-calibrated (Hannah et al., 2009) prior to installation and showed good agreement (i.e. $< \pm 0.1{ }^{\circ} \mathrm{C}$ over the range $\left.0-30^{\circ} \mathrm{C}\right)$. Within the reach, sensors were housed in white plastic PVC tubes to shield them from direct solar radiation.

\subsubsection{Hydrology and stream geometry}

Flow accretion surveys (following the velocity-area method) were conducted at $200 \mathrm{~m}$ intervals along the reach to assess net flow gains and losses between the channel and subsurface (Leach and Moore, 2011). No significant gains or losses of discharge were observed, with differences between gaugings consistently within $\pm 10 \%$ of each other (i.e. within velocityarea measurement uncertainty; Leach and Moore, 2011). These gaugings supported previous stream and streambed hydrochemical surveys (e.g. Malcolm et al., 2005) that suggested groundwater gains along the reach were negligible. Given the very significant methodological and logistical challenges in obtaining realistic hyporheic flux estimates over such a large spatial extent, neither volumes, flow path lengths or the distribution of residence times of potential hyporheic exchange were quantified.

A Scottish Environmental Protection Agency (SEPA) gauging station at Littlemill (Fig. 1) provided discharge data at $15 \mathrm{~min}$ intervals. The discharge-mean-velocity function for Littlemill presented in Tetzlaff et al. (2005) was used to calculate water velocity and thus drive the flow routing model. Good correspondence was observed between velocities and discharges measured during flow accretion surveys and those calculated from discharge at Littlemill scaled (linearly) by catchment area. Wetted width was measured at $50 \mathrm{~m}$ intervals along the reach and used as input to the water temperature model.

\subsubsection{Micrometeorological measurements}

Three automatic weather stations (AWSs) were installed within the reach (Fig. 1). The instruments deployed on the AWSs are detailed in Hannah et al. (2008). Measured hydrometeorological variables included air temperature $\left({ }^{\circ} \mathrm{C}\right)$, relative humidity $(\%)$, wind speed $\left(\mathrm{ms}^{-1}\right)$, incoming solar radiation, net radiation and bed heat flux $\left(\right.$ all $\mathrm{Wm}^{-2}$ ). Meteorological measurements were made $\sim 2 \mathrm{~m}$ above the stream surface. The bed heat flux plate was located directly below 
(a)

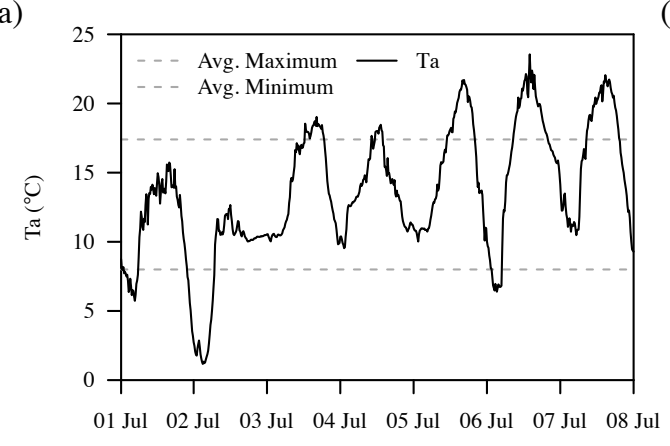

(c)

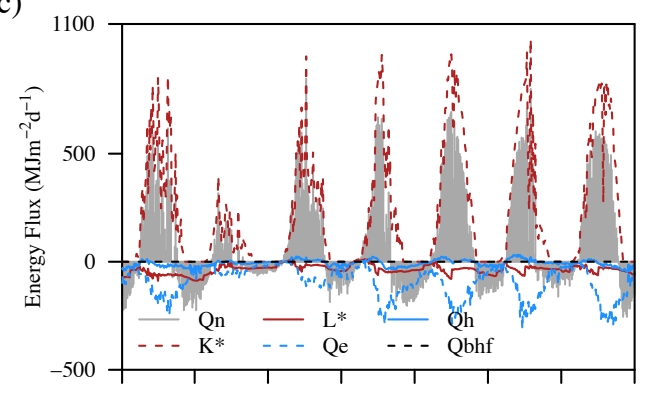

01 Jul $\quad 02 \mathrm{Jul} \quad 03 \mathrm{Jul} \quad 04 \mathrm{Jul} \quad 05 \mathrm{Jul} \quad 06 \mathrm{Jul} \quad 07 \mathrm{Jul} \quad 08 \mathrm{Jul}$

(e)

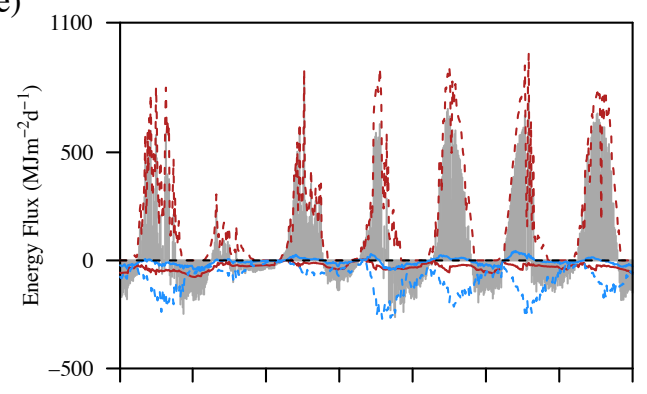

$01 \mathrm{Jul} \quad 02 \mathrm{Jul} \quad 03 \mathrm{Jul} \quad 04 \mathrm{Jul} \quad 05 \mathrm{Jul} \quad 06 \mathrm{Jul} \quad 07 \mathrm{Jul} \quad 08 \mathrm{Jul}$ (b)

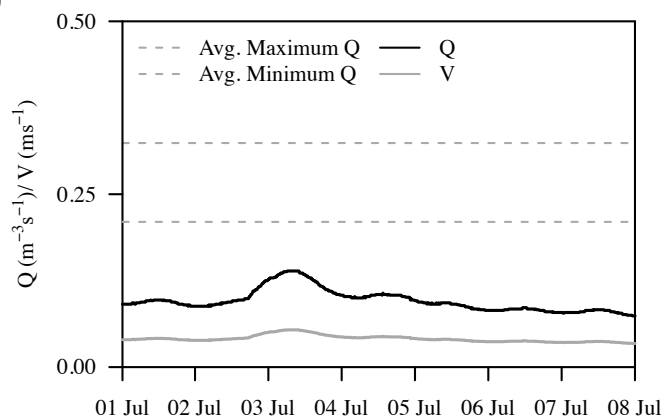

(d)

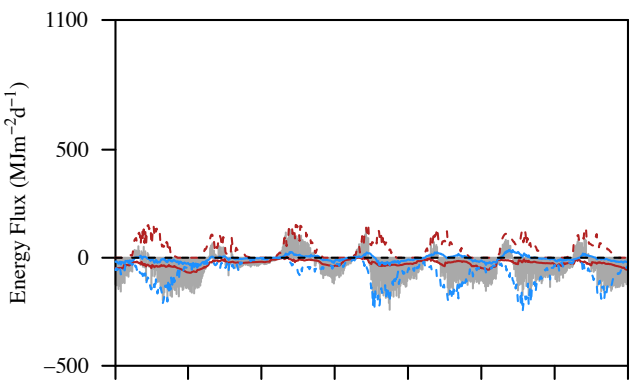

(f)

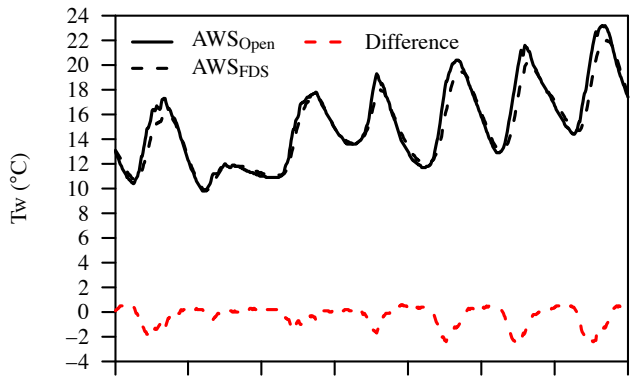

01 Jul $02 \mathrm{Jul} \quad 03 \mathrm{Jul} \quad 04 \mathrm{Jul} \quad 05 \mathrm{Jul} \quad 06 \mathrm{Jul} \quad 07 \mathrm{Jul} \quad 08 \mathrm{Jul}$

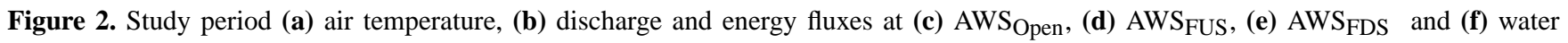
temperature at $\mathrm{AWS}_{\text {Open }}$, $\mathrm{AWS}_{\mathrm{FDS}}$ and $\mathrm{AWS}_{\text {Open }}$ minus $\mathrm{AWS}_{\mathrm{FDS}}$ (positive values indicate that temperature AWS $\mathrm{Apen}_{\text {was greater than }}$ temperature at AWS FDS). Averages represent values for DOYs (days of the year) 183 to 289 in the 10 years preceding 2013.

each AWS and buried at $0.05 \mathrm{~m}$ depth to avoid radiative and convective errors (after Hannah et al., 2008). The heat flux plate provided aggregated measurements of convective, conductive, advective and radiative heat exchanges between the atmosphere and the riverbed and between the riverbed and the water column (after Evans et al., 1998; Hannah et al., 2008). All sensors were cross-calibrated prior to installation and correction factors applied if required. The sensors were sampled at $10 \mathrm{~s}$ intervals, with averages logged every $15 \mathrm{~min}$.

\subsubsection{Hemispherical images}

Hemispherical images were taken at $5 \mathrm{~m}$ intervals along the stream centreline using a Canon EOS-10D 6.3 megapixel digital camera with Sigma $8 \mathrm{~mm}$ fisheye lens. Prior to taking each image the camera was orientated to north and levelled $\sim 20 \mathrm{~cm}$ above the stream surface (after Leach and Moore, 2010).

\subsection{Estimation of stream energy balance components}

\subsubsection{Net energy}

Net energy $\left(\mathrm{Wm}^{-2}\right)$ available to heat or cool the water column was calculated as

$Q_{\mathrm{n}}=Q^{*}+Q_{e}+Q_{\mathrm{h}}+Q_{\mathrm{bhf}}$,

where $Q_{\mathrm{n}}$ is net energy, $Q^{*}$ is net radiation, $Q_{e}$ is latent heat, $Q_{\mathrm{h}}$ is sensible heat and $Q_{\mathrm{bhf}}$ is bed heat flux (all $\mathrm{Wm}^{-2}$ ). Heat from fluid friction is negligible in this reach (see Garner et al., 2014a) and was therefore omitted. Herein, energy fluxes are considered to be positive (negative) when directed toward (away from) the water column. 


\subsubsection{Net radiation}

A deterministic model developed by Moore et al. (2005) and evaluated by Leach and Moore (2010) was used to compute net radiation $\left(Q^{*}\right)$ at the location of each hemispherical image. At each location, net radiation was calculated as

$Q^{*}=K^{*}+L^{*}$,

where $K^{*}$ is net shortwave radiation (Eq. 3) and $L^{*}$ is net longwave radiation (Eq. 4).

$$
\begin{aligned}
K^{*} & =(1-\alpha)\left[D(t) g(t)+s(t) f_{\mathrm{v}}\right] \\
L^{*} & =\left[f_{\mathrm{v}} \varepsilon_{\mathrm{a}}+\left(1-f_{\mathrm{v}}\right) \varepsilon_{\mathrm{vt}}\right] \sigma\left(T_{\mathrm{a}}+273.2\right)^{4} \\
& -\varepsilon_{\mathrm{W}} \sigma\left(T_{\mathrm{W}}+273.2\right)^{4}
\end{aligned}
$$

where $\alpha$ is the stream albedo; $D(t)$ is the direct component of incident solar radiation at time $t\left(\mathrm{Wm}^{-2}\right) ; g(t)$ is the canopy gap fraction at the position of the sun in the sky at time $t$; $S(t)$ is the diffuse component of solar radiation; $f_{\mathrm{v}}$ is the sky view factor; $\varepsilon_{\mathrm{a}}, \varepsilon_{\mathrm{vt}}$ and $\varepsilon_{\mathrm{W}}$ are the emissivity of the temperatures of the air, vegetation and water respectively $\left(\right.$ all $\left.{ }^{\circ} \mathrm{C}\right) ; \sigma$ is the Stefan-Boltzmann constant $\left(5.67 \times 10^{-8} \mathrm{Wm}^{-2} \mathrm{~K}^{-4}\right)$; and $T_{\mathrm{a}}$ and $T_{\mathrm{W}}$ are air and water temperature respectively (both ${ }^{\circ} \mathrm{C}$ ).

Values for atmospheric emissivity were calculated for clear-sky day and night conditions using the equation presented in Prata (1996; used also by Leach and Moore, 2010) and were subsequently adjusted for cloud cover using equations in Leach and Moore (2010). The emissivity and albedo were taken to be 0.95 and 0.05 for water and 0.97 and 0.03 for vegetation respectively (after Moore et al., 2005; Leach and Moore, 2010).

Gap fractions $\left(g_{*}\right)$ were computed as a function of solar zenith angle $(\theta)$ and solar azimuth $(\psi), g_{*}(\theta \psi)$, which were derived from the analysis of the hemispherical images with Gap Light Analyzer software (Frazer et al., 1999). The optimum threshold value for converting the hemispherical photographs into binary images was calculated in three steps (after Leach and Moore, 2010): (1) threshold values of 120 to 190 at 10 unit increments were applied to the photographs taken at $\mathrm{AWS}_{\mathrm{FUS}}$; (2) for each threshold value, incoming shortwave radiation was modelled at $15 \mathrm{~min}$ intervals across the 7-day study period; and (3) modelled time series were compared quantitatively with values measured at $\mathrm{AWS}_{\mathrm{FUS}}$ by calculating RMSE. A threshold value of 130 minimised RMSE and was thus identified as the optimum. It was assumed that this threshold value was optimum throughout the reach and was applied to all 211 hemispherical photographs. This assumption was reasonable because all photographs were taken on the same day, during which sky conditions were consistently overcast. Using equations in Iqbal (1983), the solar zenith and azimuth angles were computed as a function of time, $t$, so that the canopy gap at the location of the sun's disk could be derived from $g *(\theta, \psi)$ as a function of time $g(t)$. Sky view factor was computed as

$f_{\mathrm{v}}=\frac{1}{\pi} \int_{0}^{2 \pi} \int_{0}^{\pi / 2} g_{*}(\theta, \psi) \cos \theta \sin \theta \cdot \mathrm{d} \theta \cdot \mathrm{d} \psi$.

The double integral was approximated by summation using an interval of $5^{\circ}$ for both solar-zenith and azimuth angles (after Leach and Moore, 2010). Solar-radiation measurements made at $\mathrm{AWS}_{\text {open }}$ were used as input to the radiation models. Modelled and observed values of incoming solar radiation were compared at each AWS for the entire study period; the RMSE $\left(<75 \mathrm{Wm}^{-2}\right)$ compared favourably with those observed by Leach and Moore (2010).

\subsubsection{Latent and sensible heat fluxes}

To compute heat lost by evaporation or gained by condensation, latent heat was estimated after Webb and Zhang (1997) (Eq. 6).

$Q_{e}=285.9(0.132+0.143 \cdot U)\left(e_{\mathrm{a}}-e_{\mathrm{w}}\right)$,

where $U$ is wind speed $\left(\mathrm{ms}^{-1}\right)$ and $e_{\mathrm{a}}$ and $e_{\mathrm{w}}$ are the vapour pressures of air and water (both $\mathrm{kPa}$ ) respectively.

$e_{\text {sat }}(T)=0.611 \cdot \exp \left[\frac{2.5 \times 10^{6}}{461} \cdot\left(\frac{1}{273.2}-\frac{1}{T}\right)\right]$

The vapour pressure of water $\left(e_{\mathrm{w}}\right)$ was assumed to be equal to $e_{\mathrm{sat}}\left(T_{\mathrm{w}}\right)$. The vapour pressure of air was calculated using Eq. (8).

$e_{\mathrm{a}}=\frac{\mathrm{RH}}{100} e_{\mathrm{sat}}\left(T_{\mathrm{a}}\right)$

Sensible heat (Eq. 9) was calculated as a function of latent heat (Eq. 6) and Bowen ratio $(\beta)($ Eq. 10), where $P$ is air pressure $(\mathrm{kPa})$.

$Q_{\mathrm{h}}=Q_{e} \cdot \beta$
$\beta=0.66 \cdot\left(\frac{P}{1000}\right) \cdot\left[\left(T_{\mathrm{w}}-T_{\mathrm{a}}\right) /\left(e_{\mathrm{a}}-e_{\mathrm{w}}\right)\right]$

\subsection{Modelling approaches}

\subsubsection{Statistical models}

Spatial (and temporal) variability in canopy density (and net energy flux) was extremely high. Therefore, in order to characterise broad patterns in space (and time), generalised additive models (GAMs; Hastie and Tibshirani, 1986) were used to provide continuous smoothed estimates of the variability in each data set. GAMs were fitted in the MGCV package (Wood, 2006; version 1.7-13) for R (R Group for Statistical Computing; version 3.0.2). Degrees of freedom were obtained by generalised cross-validation within the MGCV library but were limited in order to prevent overfitting by setting "gamma" to 1.4 following Wood (2006). 
The GAM fitted to canopy density provided a continuous smoothed estimate of the spatial variability in density from discrete ( $5 \mathrm{~m}$ interval) point measurements determined from Gap Light Analyzer outputs. Canopy density was calculated as the percentage of pixels representative of vegetation in each hemispherical image; this percentage was modelled as a smoothed function of distance downstream (i.e. from AWS $\mathrm{Spen}_{\text {) }}$.

The second GAM provided a continuous smoothed estimate of the spatio-temporal variability in net energy flux estimated at $5 \mathrm{~m}$ intervals from the sum of the scaled radiative flux (see Sect. 4.4.3), and turbulent and bed heat fluxes calculated from hydrometeorological observations scaled by linear interpolation between the two nearest AWSs. Specifically, net energy was modelled as smoothed functions of (i) time of day, (ii) day of year and (iii) distance downstream. The inclusion of three smoothed terms was validated by fitting models using each combination of the three terms and comparing each using the AIC (Akaike information criterion; Burnham and Anderson, 2002) score, a measure of model quality that balances fit and parsimony between models. The selected model was that with the lowest AIC, since there were no other candidate models (within an AIC of 2 of the selected model).

\subsubsection{Flow routing model}

A flow routing model was used to predict the time taken by water parcels to travel through the reach. The model was based on a discharge-mean-velocity function (Tetzlaff et al., 2005) and predicted the distance travelled by water parcels at 15 min intervals. In combination with the data set of spatiotemporally distributed water temperature observations, the model also identified the temperature of distinct water volumes at $15 \mathrm{~min}$ intervals.

The model released water from $\mathrm{AWS}_{\mathrm{open}}$ at the start of every hour on each day of the study period. For each parcel of water $(i)$, the distance travelled in $15 \mathrm{~min}$ from its initial location $(x)$ to the next location $(x+1)$ was calculated as the product of the length of the timestep ( $\Delta t$, i.e. $900 \mathrm{~s})$ and the average velocity at times $t$ and $t+\Delta t$. The temperature of the parcel at location $x+1$ and time $t+\Delta t$ was determined by linear interpolation (to the nearest $1 \mathrm{~m}$ ) between measurements at $15 \mathrm{~min}$ intervals and between temperature loggers respectively.

\subsubsection{Lagrangian water temperature model}

The Lagrangian modelling approach (after Bartholow, 2000; Boyd and Kasper, 2003; Rutherford et al., 2004; Westhoff et al., 2007, 2010; Leach and Moore, 2011; MacDonald et al., 2014a, b) divided the reach into a series of segments (s) bounded by nodes (indexed by $j$ ). For each time step, $\Delta t$ (i.e. 900 s), a water parcel ( $i$ ) was released from the upstream boundary; its initial temperature was an observed value. As the water parcel travelled downstream from $j$ towards $j+1$, the model computed the heat exchange and the net change in stream temperature over the segment as the mean of net energy flux within the segment at time $t$ and time $t+\Delta t$ (Eq. 10).

$$
\frac{\mathrm{d} T_{\mathrm{w}}}{\mathrm{d} x}=\frac{\left.\left[\begin{array}{l}
w_{(\mathrm{s})}\left(K_{(\mathrm{s}, t)}^{*}+L_{(\mathrm{s}, t)}^{*}+Q_{\mathrm{h}(\mathrm{s}, t)}+Q_{e(\mathrm{~s}, t)}+Q_{\mathrm{bhf}(\mathrm{s}, t)}\right) \\
+w_{(\mathrm{s})}\left(K_{(\mathrm{s}, t+\Delta t)}^{*}+L_{(\mathrm{s}, t+\Delta t)}^{*}+Q_{\mathrm{h}(\mathrm{s}, t+\Delta t)}+Q_{e(s, t+\Delta t)}+Q_{\mathrm{bhf}(\mathrm{s}, t+\Delta t)}\right)
\end{array}\right] / 2\right]}{C\left[\left(F_{(\mathrm{s}, t)}+F_{(\mathrm{s}, t+\Delta t)}\right) / 2\right]},
$$

where $W_{(\mathrm{s})}$ is the mean wetted width of the stream surface (m) within segment $s$ and $K_{(\mathrm{s}, t / t+\Delta t)}^{*}, L_{(\mathrm{s}, t / t+\Delta t)}^{*}$, $Q_{e(\mathrm{~s}, t / t+\Delta t)}, Q_{\mathrm{h}(\mathrm{s}, t / t+\Delta t)}$ and $Q_{\mathrm{bhf}(\mathrm{s}, t / t+\Delta t)}$ are the mean net shortwave, net longwave, latent, sensible and bed heat fluxes within segment $s$ at time $t$ or $t+\Delta t$. $C$ is the specific heat capacity of water $\left(4.18 \times 10^{6} \mathrm{Jm}^{-3}{ }^{\circ} \mathrm{C}^{-1}\right)$, and $F_{(\mathrm{s}, t / t+\Delta t)}$ is the discharge $\left(\mathrm{m}^{3} \mathrm{~s}^{-1}\right.$; scaled by catchment area) within segment $s$ at time $t$ or $t+\Delta t$.

Water temperature was calculated at $1 \mathrm{~m}$ intervals along the reach by the integration of Eq. (10) in the deSolve package (Soetaert et al., 2010) for R (Version 3.0.2, R Core Team, 2013).

Unsmoothed (raw) energy flux data were used for numerical modelling. Incident solar radiation was modelled at $5 \mathrm{~m}$ intervals (see Sect. 4.4.3, Net radiation); values at $1 \mathrm{~m}$ intervals were obtained by linear interpolation. Emitted longwave radiation and latent and sensible heat fluxes were dependent on water temperature. Therefore, these fluxes were calculated at each time step within Eq. (10) using values for air temperature, humidity and wind speed estimated at $1 \mathrm{~m}$ intervals by linear interpolation between the two nearest AWSs.

\subsubsection{Sensitivity analysis}

With the exception of the threshold value applied to the hemispherical images (see Sect. 3.3.2), no site-specific parameters were used for water temperature modelling. A sensitivity analysis was conducted on the image threshold parameter to assess its influence on water temperature model output. Time series of incident shortwave radiation modelled at $\mathrm{AWS}_{\mathrm{FUS}}$ using the assumed maximum (i.e. 190) and minimum (i.e. 120) thresholds were retained during the procedure described in Sect. 3.3.2. Percentage changes in incident shortwave radiation between the optimum (130) and assumed maximum and minimum values were calculated for 15 min intervals across the entire study period. The percentage changes associated with the upper and lower thresholds were used to generate two data sets of incident shortwave radiation representative of potential maximum and minimum values. This assumed that percentage changes calculated at $\mathrm{AWS}_{\mathrm{FUS}}$ were representative of changes throughout the entire reach; this was a reasonable assumption, given that all photographs were taken on the same day, during which sky conditions remained overcast. To quantify the effect of the threshold on model outputs, two additional model runs were performed for each water parcel released from $\mathrm{AWS}_{\text {Open }}$ using each of these data sets of incident solar radiation. 


\section{Results}

Results are presented in four sections: (1) prevailing hydrological and weather conditions, (2) observed spatio-temporal water temperature patterns, (3) riparian canopy density and net energy flux patterns, and (4) modelled spatio-temporal water temperature patterns.

\subsection{Prevailing hydrological and weather conditions}

A total of $4.2 \mathrm{~mm}$ of rain was measured in the catchment during the study period (1-7 July 2013). Stream discharge measured at Littlemill was very low $\left(0.074-0.138 \mathrm{~m}^{3} \mathrm{~s}^{-1}\right)$, reasonably stable and exhibited no sudden changes (Fig. 2). The days of 1, 3, 4, 5, 6 and 7 July were characterised by high net energy gains to the water column during daylight hours, driven by clear skies and consequently high solar-radiation receipt (Fig. 2). On 2 July net energy gains were markedly lower due to overcast skies and associated low solar-radiation receipt (Fig. 2). This data window allowed the investigation of the influence of contrasting energy gain conditions (i.e. low versus high net energy gain) on the spatio-temporal variability of water temperature and energy flux.

\subsection{Observed spatio-temporal water temperature patterns}

Instantaneous longitudinal temperature gradients occurred frequently throughout the entire monitoring period (Fig. 3). Gradients were greatest in spring and summer months during which time warming gradients were much smaller $\left(<0.5^{\circ} \mathrm{C}\right)$ than cooling gradients $\left(\leq 2.5^{\circ} \mathrm{C}\right)$. Gradients were especially large during the chosen 7-day study period.

During the study period, minimum daily water temperature was the same at both $\mathrm{AWS}_{\text {Open }}$ and $\mathrm{AWS}_{\mathrm{FDS}}\left(9.8^{\circ} \mathrm{C}\right)$ but maximum temperature was higher at $\mathrm{AWS}_{\text {Open }}$ than at $\mathrm{AWS}_{\mathrm{FDS}}$, with observed temperatures of 23.0 and $22.0^{\circ} \mathrm{C}$ respectively (both occurring on 6 July) (Fig. 2f). Minimum temperatures occurred synchronously across all three locations (Fig. 2f). Maximum temperatures at AWS FDS lagged those at $\mathrm{AWS}_{\text {Open }}$ by between 1 and $1.75 \mathrm{~h}$ on all days except 2 July (Fig. 2f). On 2 July, when skies were overcast and the water column received lower solar radiation, maximum temperatures occurred synchronously at both locations (Fig. 2f).

Longitudinal gradients in instantaneous water temperature measurements (at a particular point in time across the entire reach) were observed during daylight hours on each day of the study period. Instantaneous water temperatures were greatest at $\mathrm{AWS}_{\text {Open }}$ and decreased downstream towards

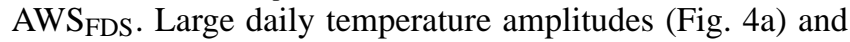
distinct downstream gradients of $>1{ }^{\circ} \mathrm{C}$ (Fig. 4b) were observed on 1, 3, 4, 5, 6 and 7 July between 11:00 and 16:00 GMT. The greatest instantaneous temperature gradient was $2.5^{\circ} \mathrm{C}$ in magnitude, observed on 6 July at 12:00 GMT

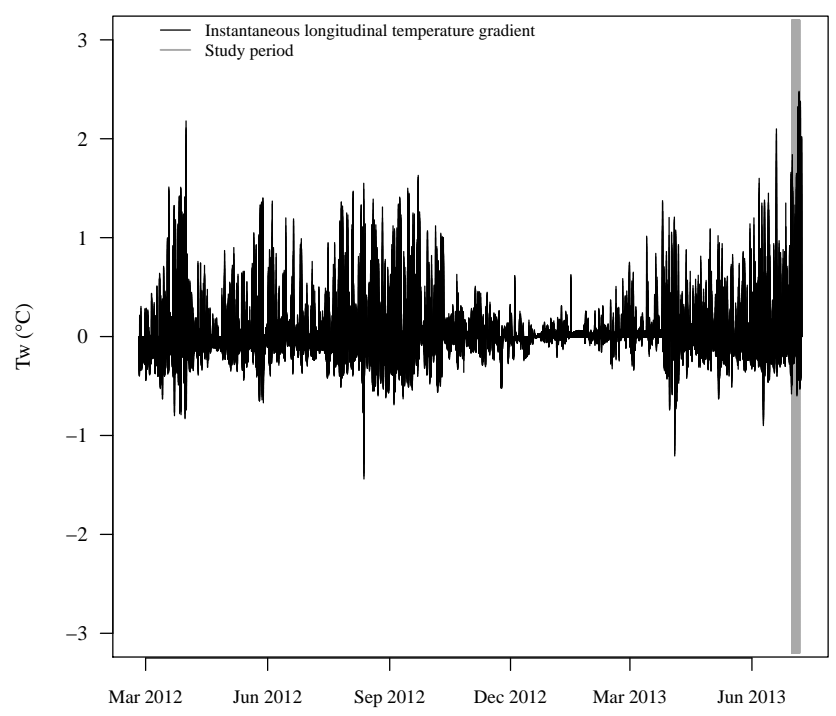

Figure 3. Instantaneous stream temperature gradients during field data collection. Positive values indicate that temperature at AWS $S_{\text {Open }}$ was greater than that at $\mathrm{AWS}_{\mathrm{FDS}}$ (i.e. instantaneous cooling gradient), while positive values indicate that temperature at $\mathrm{AWS}_{\text {Open }}$ was less than that aW $\mathrm{AWS}_{\mathrm{FDS}}$ (i.e. instantaneous warming gradient).

(Fig. 4b). On 2 July, the amplitude of the diurnal water temperature cycle was greatly reduced (Fig. $4 a$ ) and longitudinal water temperature gradients were small (Fig. 4b), with the greatest gradient $\left(0.6^{\circ} \mathrm{C}\right)$ observed at 08:00 GMT and smaller gradients $\left(<0.2^{\circ} \mathrm{C}\right.$, i.e. below measurement accuracy of the sensors) observed between 11:00 and 15:00 GMT (Fig. 4b).

Overnight, longitudinal gradients were reversed (cf. daylight hours); instantaneous water temperatures were lowest at $\mathrm{AWS}_{\mathrm{Open}}$ and increased downstream towards $\mathrm{AWS}_{\mathrm{FDS}}$ (Fig. 4b). However, the difference in temperature between these two sites during the night was consistently $<0.5^{\circ} \mathrm{C}$ in magnitude.

\subsection{Riparian canopy density and net energy flux patterns}

Between $\mathrm{AWS}_{\text {Open }}(0 \mathrm{~m})$ and $400 \mathrm{~m}$ patchy forest cover (Fig. 5a and b) generated canopy densities ranging from 0.0 to $70.3 \%$ (Fig. 6a). Between 400 and $1050 \mathrm{~m}$ (AWS $\mathrm{FDS}$ ) continuous riparian forest of variable density (Fig. $5 \mathrm{c}$ and d) produced typically lower but still variable gap fractions ranging from 22.5 to $92.0 \%$ (Fig. 6a). The forest canopy was densest between 400 and $800 \mathrm{~m}$ and decreased in density between 800 and $1050 \mathrm{~m}$ (Fig. 6a).

The spatial variability in net energy corresponded broadly to canopy density (Fig. 6). Net energy gains during daylight hours decreased gradually from AWS Open to $400 \mathrm{~m}$ before declining sharply between 400 and $800 \mathrm{~m}$. Between 800 and $1050 \mathrm{~m}$ (AWS $\mathrm{FDS}$ ), net energy flux increased markedly. 
(a)

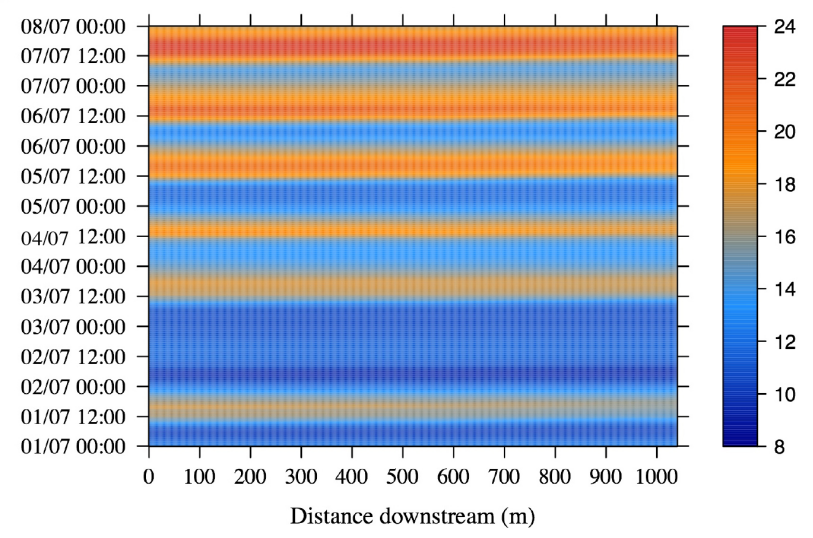

(b)

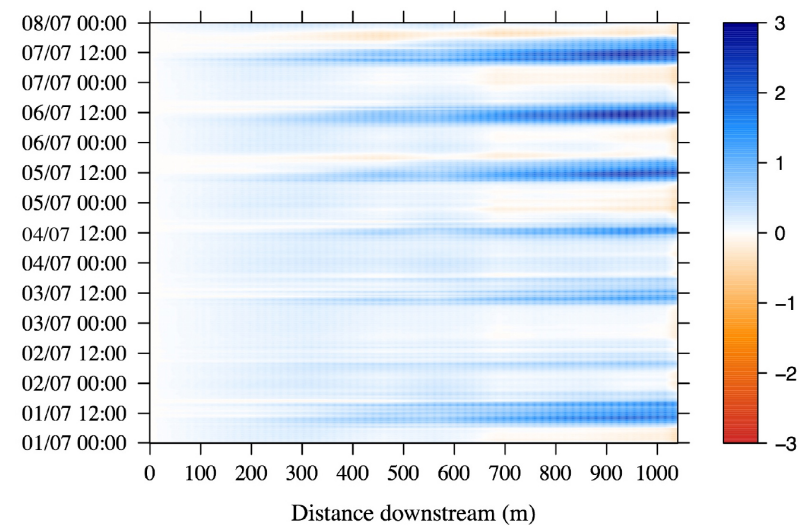

Figure 4. Spatio-temporal patterns in instantaneous water temperature measurements: (a) absolute values $\left({ }^{\circ} \mathrm{C}\right)$ and (b) differences between $\mathrm{AWS}_{\text {Open }}$ and each monitoring location within the reach (positive values indicate instantaneous cooling gradients). Values for both panels were interpolated linearly at $1 \mathrm{~m}$ intervals from observations.

Strong diurnal signals and distinct spatial patterns were observed during daylight hours on 1, 3, 4, 5, 6 and 7 July, with spatial patterns especially clear around solar noon (Fig. 6b). On 2 July, the spatial and temporal variability of net energy fluxes was much subdued. Around solar noon on 2 July, net energy flux was slightly lower at $800 \mathrm{~m}$, but differences within the reach were otherwise indistinguishable (Fig. 6b), driven by smaller differences (relative to clear-sky conditions) in solar-radiation gain between open and forested sites (Fig. 2c-e).

During the night, small and temporally consistent differences in net energy occurred within the reach (Fig. 6b). Net energy losses were greatest at $\mathrm{AWS}_{\text {Open }}$ and declined up until $400 \mathrm{~m}$ before stabilising and increasing again between 800 and $1050 \mathrm{~m}$, yet spatial variability was markedly reduced in comparison to daytime conditions on 1 July and 3-7 July.

\subsection{Modelled spatio-temporal water temperature patterns}

The flow routing model (and associated observations of the temperature of water parcels as they travelled through the reach) was evaluated by predicting the change in temperature of water parcels (using the water temperature model). Temperature changes over the reach were compared with those predicted for water leaving $\mathrm{AWS}_{\text {open }}(0 \mathrm{~m}$, the upstream boundary of the reach) at 06:00, 07:00, 08:00 and 09:00 GMT. Water parcels released at these times were associated with the greatest observed instantaneous cooling gradients on arrival at the downstream reach boundary. Predictions of downstream temperature change (Figs. 7 and 8) were typically good, as indicated by high $R^{2}$ (ranging from 0.71 on 2 July to 0.99 on 6 July) and low RMSE (ranging from $0.2^{\circ} \mathrm{C}$ on 1 and 2 July to $0.4^{\circ} \mathrm{C}$ on 7 July). Thus, the evaluation statistics compared favourably to those observed in previous studies using similar models (e.g. Westhoff et al., 2011). The model was biased towards slight overprediction (as indicated by percent bias), but in all cases this was $<2.0 \%$. Importantly, the model was capable of predicting instantaneous longitudinal cooling gradients with reasonable accuracy (i.e. $\leq \pm 0.5^{\circ} \mathrm{C}$ ), and the error in predicted gradients displayed no consistent bias. The sensitivity analysis on the threshold value for image processing demonstrated that the optimum threshold resulted in conservative predictions of downstream cooling. Higher threshold values (i.e. 140190) resulted in much lower modelled temperatures at the downstream boundary (up to $0.9{ }^{\circ} \mathrm{C}$ ) and consequently enhanced cooling gradients. A lower threshold (i.e. 120) increased modelled temperatures and therefore reduced modelled cooling gradients slightly, by up to $0.2^{\circ} \mathrm{C}$ at the downstream reach boundary (Fig. 8).

Using the flow routing model, the time taken for water to travel $1050 \mathrm{~m}$ through the reach from $\mathrm{AWS}_{\mathrm{Open}}$ to $\mathrm{AWS}_{\mathrm{FDS}}$ averaged $7.5 \mathrm{~h}$. Typically, water travelling from the upstream boundary of the reach between 01:00 and 12:00 GMT warmed as it travelled through the reach, while water beginning its journey through the reach between 13:00 and 00:00 GMT cooled (Fig. 8). On 1, 3, 4, 5, 6 and 7 July, water warmed between 4.2 and $6.9^{\circ} \mathrm{C}$ while travelling through the reach, but, at the time of arrival at $\mathrm{AWS}_{\mathrm{FDS}}$, it was cooler than the water temperature observed at $\mathrm{AWS}_{\text {open }}$ at the same time. For example, on 6 July the temperature of water leaving $\mathrm{AWS}_{\text {open }}$ at 08:00 GMT was $14.3^{\circ} \mathrm{C}$. This water passed through the reach and arrived at $\mathrm{AWS}_{\mathrm{FDS}}$ at 15:30 GMT, by which time its temperature had risen to $20.1{ }^{\circ} \mathrm{C}$. The water leaving AWS $\mathrm{Apen}_{\text {at }}$ a $15: 30 \mathrm{GMT}$ had a temperature of $21.2^{\circ} \mathrm{C}$ (Fig. 9a). Thus, at 15:30 GMT, the water at $\mathrm{AWS}_{\mathrm{FDS}}$ was $1.1^{\circ} \mathrm{C}$ cooler than that at $\mathrm{AWS}_{\text {Open }}$. Distinct instantaneous cooling gradients were not observed on 2 July, when water warmed $<1.5^{\circ} \mathrm{C}$ while travelling through the reach. The water travelling from $\mathrm{AWS}_{\text {open }}$ on day 2 at 07:00 GMT had a temperature of $10.4{ }^{\circ} \mathrm{C}$ and reached $\mathrm{AWS}$ FDS at 14:15 GMT, 
(a)

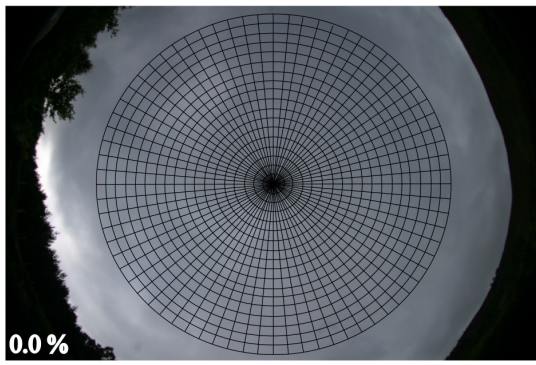

(c)

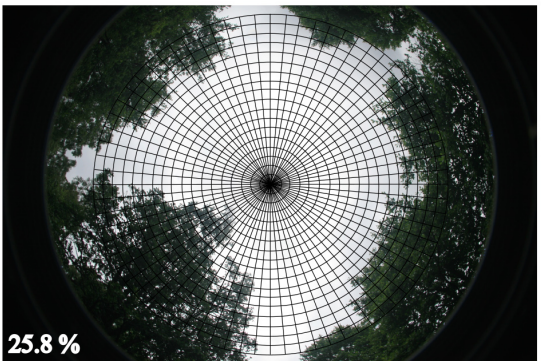

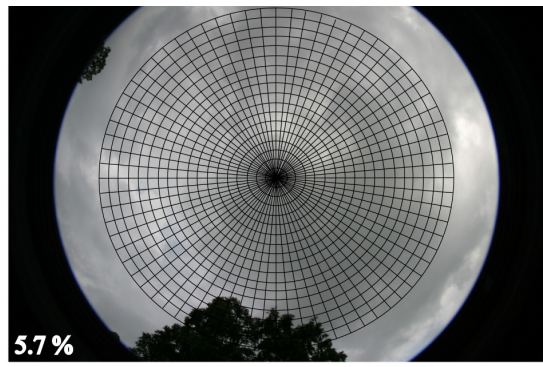

(d)

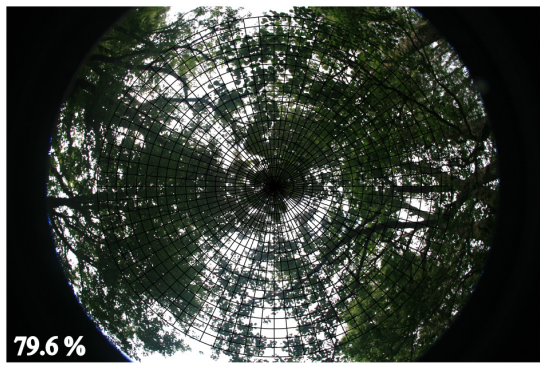

Figure 5. Hemispherical photographs representative of (a) clear-sky view, (b) low-density, patchy riparian forest, (c) low-density, continuous riparian forest and (d) high-density, continuous riparian forest. The grid represents the $5^{\circ}$ azimuth and zenith overlay applied by Gap Light Analyzer software.

attaining a temperature of $11.8^{\circ} \mathrm{C}$. Water travelling downstream from $\mathrm{AWS}_{\text {open }}$ at 14:15 GMT also had a temperature of $11.8{ }^{\circ} \mathrm{C}$, and, thus, no cooling gradient was observed (Fig. 9b).

\section{Discussion}

This study has quantified longitudinal water temperature patterns in a stream reach where land use transitions from open moorland to semi-natural forest. Furthermore, the riparian land use controls and associated energy exchange and water transport processes that generate water temperature patterns have been identified. Significant groundwater inflows do not occur within the reach, and thus energy exchange was dominated by fluxes at the air-water-column interface, allowing an unconfounded conceptual understanding of the processes of longitudinal stream water cooling gradients under forest canopies. The following discussion identifies the key drivers and processes, their space-time dynamics, and the limitations of the study.

\subsection{Micrometeorological and land use controls on energy exchange and water temperature}

During daylight hours, the observation of net energy gains corroborated the observations of Brown et al. (1971), Story et al. (2003) and Westhoff et al. (2010) for shaded streams downstream of clearings. Distinctive longitudinal patterns of net energy exchange were observed on days with clear skies when solar radiation and net energy gains were greatest, whereas net energy varied little within the reach on over- cast days, indicating that meteorological conditions were a first-order control on patterns of net energy flux (Rutherford et al., 1997, 2004). The density of the semi-natural riparian forest canopy was a second-order control on net energy flux. On days with clear skies, net energy gain was greatest where trees were absent (Moore et al., 2005) or the canopy was sparse and least where the canopy was densest (Leach and Moore, 2010), owing to the canopy providing shading from solar radiation (Beschta and Taylor, 1988; Macdonald et al., 2003; Malcolm et al., 2004; Moore et al., 2005; Hannah et al., 2008; Imholt et al., 2010, 2012).

Contrasting meteorological conditions, and thus net energy gain conditions, within the study period drove differences in the timing and magnitude of water temperature dynamics (Malcolm et al., 2004) and gradients observed within the reach. On overcast days, within-reach differences in the magnitude (Johnson and Jones, 2000) and timing of maximum daily temperatures and longitudinal water temperature gradients were indistinguishable. However, on clear-sky days, maximum daily temperatures decreased between the upstream and downstream reach boundary by up to $1^{\circ} \mathrm{C}$; locations further downstream experienced maximum temperatures later in the day and instantaneous cooling gradients of up to $2.5^{\circ} \mathrm{C}$ (equivalent to $2.4^{\circ} \mathrm{C} \mathrm{km}^{-1}$ ) were observed. These decreases in temperature were much less than those observed by McGurck (1989), Keith et al. (1998) and Story et al. (2003), who observed instantaneous cooling gradients of between 4.0 and $9.2^{\circ} \mathrm{C} \mathrm{km}^{-1}$. Variability in cooling gradients at and between sites may be attributed to differing climatic zones, prevailing weather conditions (Rutherford et al., 2004), riparian vegetation density and orientation, channel 


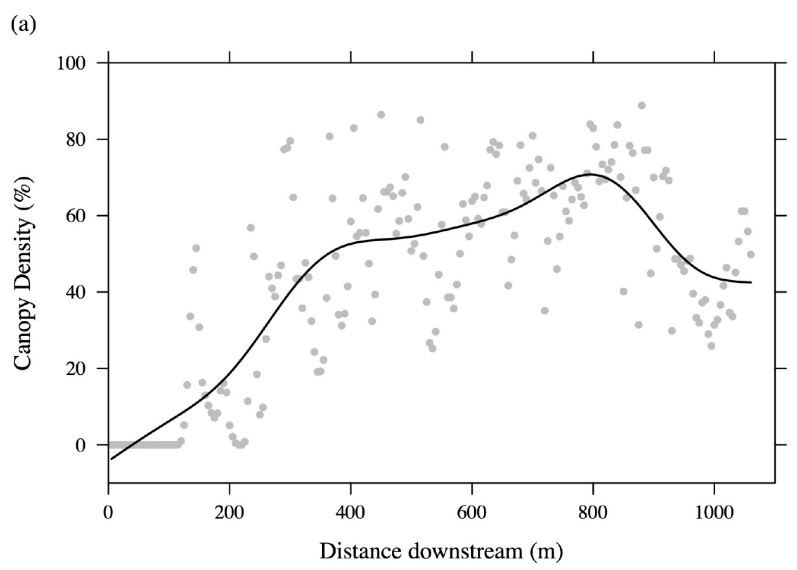

(b)

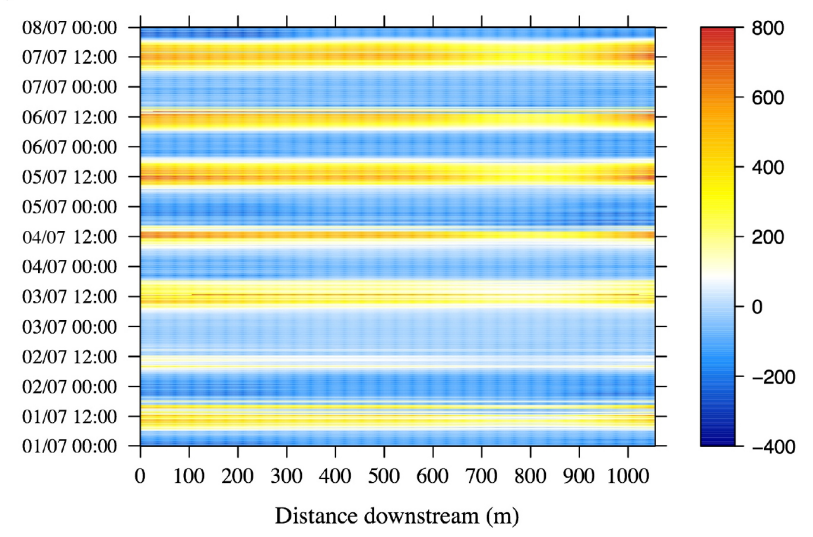

Figure 6. Patterns within the reach in: (a) canopy density (points indicate spot measurements of canopy density obtained from hemispherical photographs. Solid line indicates smoothed trend) (b) net energy flux $\left(\mathrm{MJ} \mathrm{m}^{2} \mathrm{~d}^{-1}\right)$.

orientation, and subsurface hydrology; all control the magnitude of energy exchange and, consequently, water temperature (Poole and Berman, 2001; Webb and Zhang, 1997).

\subsection{Alternative conceptualisation of processes generating longitudinal water temperature gradients in forested river reaches}

The water temperature model reproduced downstream temperature patterns with a high level of accuracy using physically realistic parameters scaled from numerous local micrometeorological and river flow measurements. This suggests that the energy balance was near closed. Previous studies (e.g. Story et al., 2003) observed net energy gains to the water column (which cannot drive cooling of water as it travels downstream; Story et al., 2003), but they were conducted in river reaches with known cooler groundwater inflows and hyporheic exchanges. There are considerable challenges in identifying and quantifying volumes and temperatures of these spatially and temporally heterogeneous heat and water fluxes (see Sect. 5.3) and, consequently, in ob-

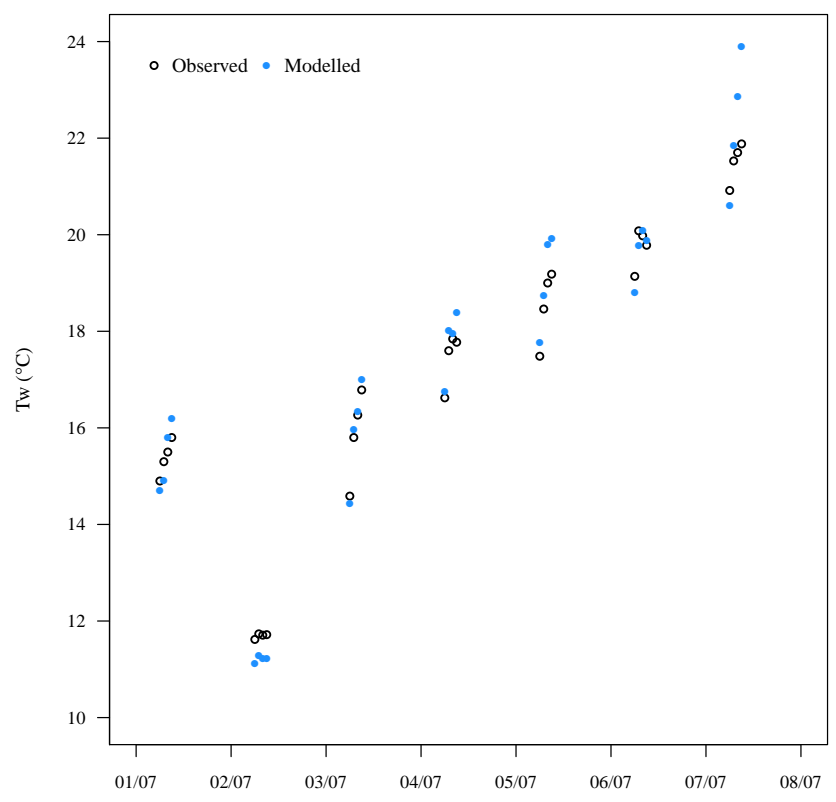

Figure 7. Observed and modelled water temperature at $\mathrm{AWS}_{\mathrm{FDS}}$.

taining field measurements which close the energy budget. Therefore, these studies conceptualised high groundwater and hyporheic exchange contributions that enabled downstream cooling to be invoked in the models developed. Consequently, this work inferred that water cooled as it travelled downstream due to substantial cool groundwater inputs rather than spatial differences in energy exchanges at the water-column-atmosphere interface beneath the forest canopy. The present study has demonstrated that cooling gradients may be produced in the absence of groundwater inputs in a shaded stream reach downstream of open land use. Consequently, it presents an alternative conceptualisation of the processes that may generate spatio-temporal water temperature patterns. An important distinction between this research and other process explanations of instantaneous cooling gradients is that water does not need to cool as it travels downstream beneath a forest canopy. Instead, water can warm as it travels downstream, but cooling gradients may be generated when the temperature of water advected into the reach increases over the day, while this water is subsequently heated minimally while flowing beneath the forested canopy.

Our results suggest that the following alternative process conceptualisation may generate spatio-temporal water temperature patterns in the absence of groundwater inflows on (i) a clear-sky day and (ii) an overcast-sky day. On clearsky days, net energy fluxes increase reasonably consistently between sunrise and solar noon, driven by increasing solarradiation receipt. Consequently, the temperature of water crossing the upstream boundary of the study reach between sunrise and solar noon increases continually (i.e. more heat is advected into the reach) (Westhoff et al., 2010). On entering the forest, water temperature continues to increase but at 

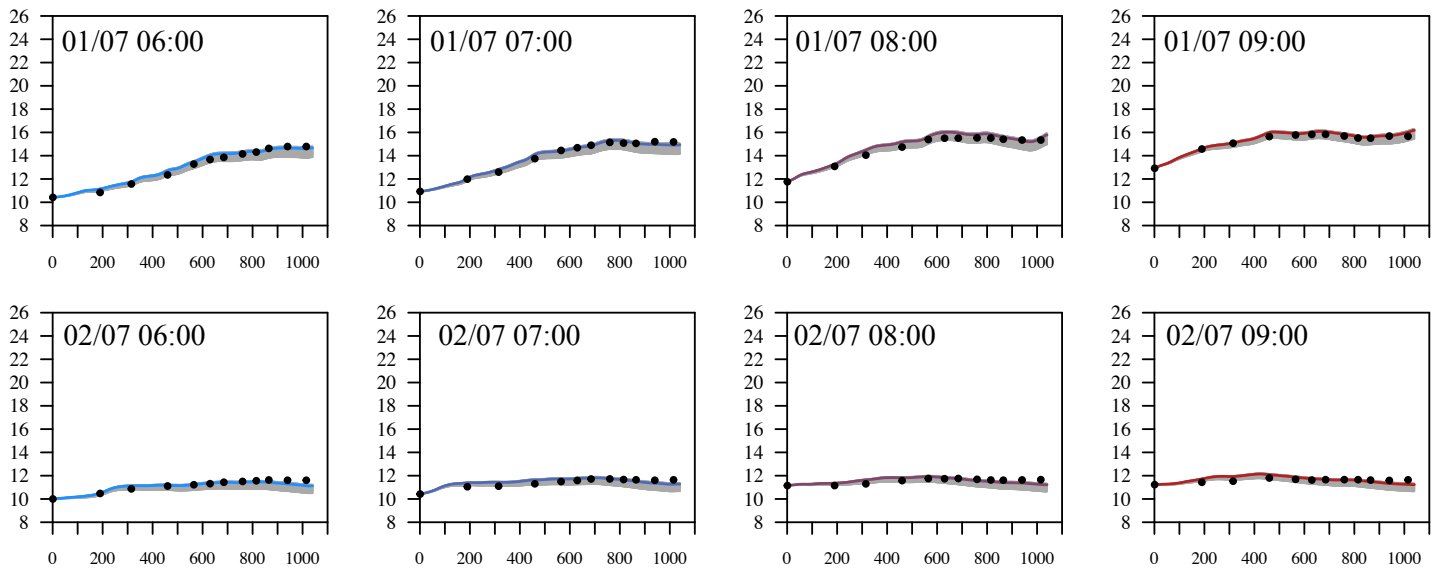

$\begin{array}{llllll}0 & 200 & 400 & 600 & 800 & 1000\end{array}$

$\begin{array}{lllllll}0 & 200 & 400 & 600 & 800 & 1000\end{array}$
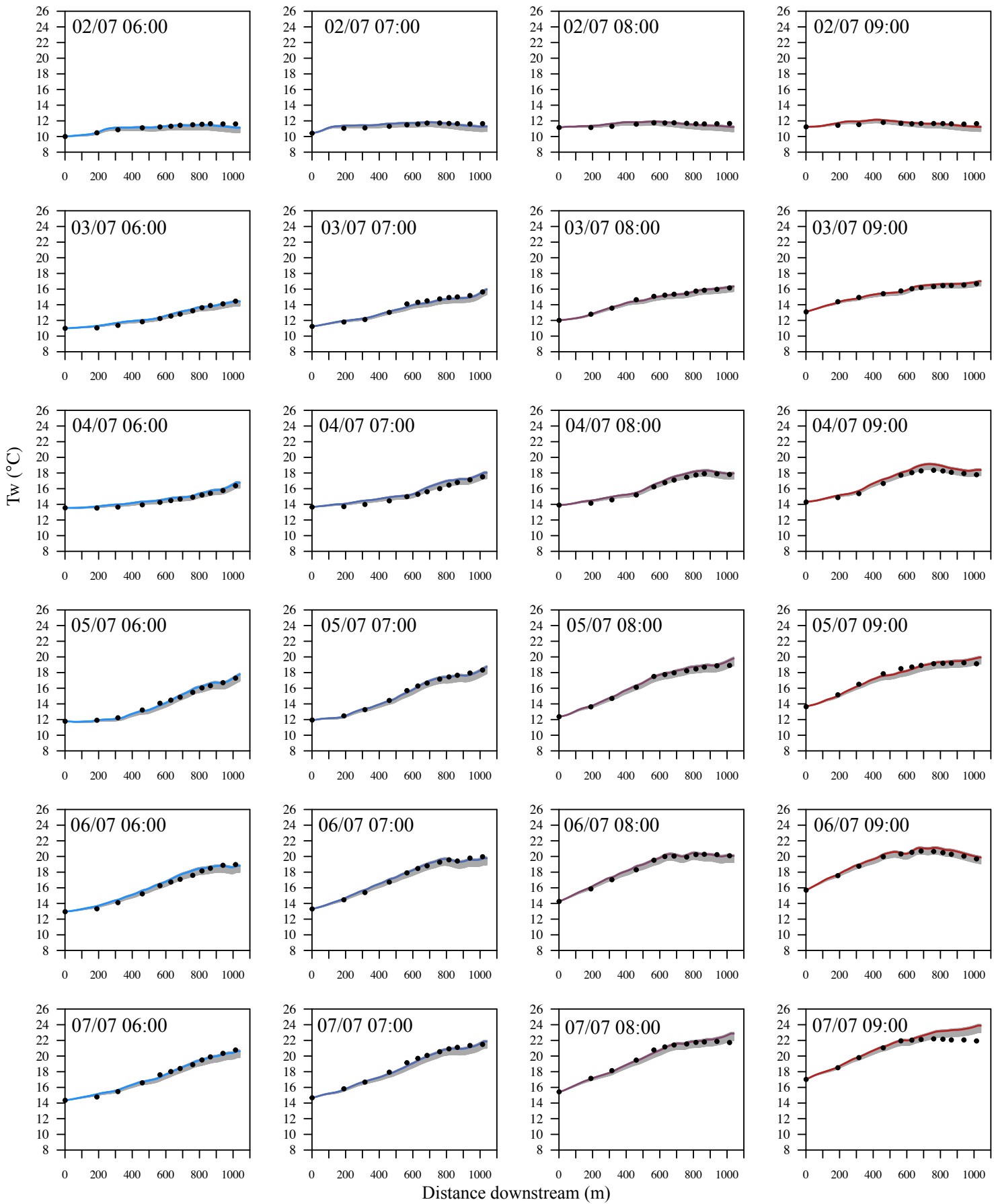

Figure 8. Modelled (lines) and observed (points) water temperatures of parcels released from AWS Open at hourly intervals between 06:00 and 09:00 GMT on each day of the study period. Grey envelopes demonstrate the influence of the threshold parameter used to convert hemispherical photographs to binary images prior to incident solar-radiation modelling. Lower bound is representative of the maximum threshold value; upper bound is representative of the minimum threshold value. 
(a)

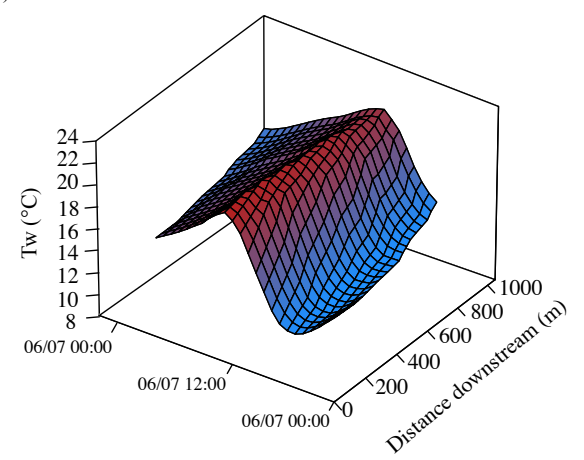

(b)

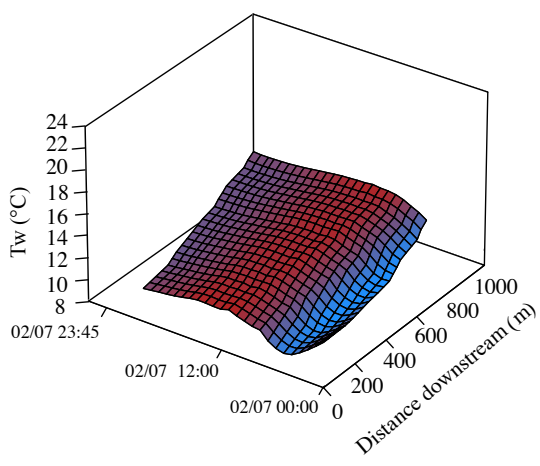

Figure 9. Temperature of water parcels (black lines on the date and time axis) routed through the reach from $\mathrm{AWS}$ Open at hourly intervals (a) on day 6 and (b) day 2 .

a much reduced rate (Rutherford et al., 2004) as solar radiation and, thus, net energy are reduced considerably. Consequently, when net energy gains occur, water flowing through the forest is consistently cooler than water travelling through the upper reach and moorland during the same time. On overcast days, net energy gains increase little between sunrise and solar noon and differences in net energy gains between moorland and forested sites are minimal. Therefore, the temperature of water crossing the upstream reach boundary changes little over the day (i.e. heat advected into the reach is reasonably constant) and water temperature changes at similar rates, whether flowing through forest or moorland. Consequently, minor differences in water temperature are observed throughout the reach.

\subsection{Limitations}

Models are always simplifications of reality and therefore must incorporate assumptions (Westhoff et al., 2011). Although the model presented herein performed well, a number of assumptions were made which may have affected its performance. These assumptions are identified in this section, and suggestions are made for future model parameterisation and application.

In using three AWSs situated directly above the stream (one in open moorland and two within the forest), this study sought to improve upon previous representations of turbulent heat fluxes, where often a single weather station (e.g. Westhoff et al., 2007, 2010, 2011; Benyahya et al., 2010), sometimes not located within the study catchment (e.g. Westhoff et al., 2007; Benyahya et al., 2010), has been used. Considerable heterogeneity was observed between meteorological measurements made at all weather stations, including within the forest. Consequently, micrometeorological measurements were not only determined by land use but also potentially by the surrounding topography, altitude and aspect. Therefore, it was considered a reasonable and systematic approach to interpolate values for micrometeorological vari- ables between AWSs at $1 \mathrm{~m}$ intervals. However, this likely introduced some error, and future work should seek to identify methods of more accurately representing micrometeorological variables, and consequently turbulent fluxes, at high spatial resolution within stream reaches (particularly forests).

Bed heat flux plates connected to each AWS provided aggregated measurements of heat exchange due to convective, conductive, advective and radiative heat exchanges between the atmosphere and the riverbed and between the riverbed and the water column (after Evans et al., 1998; Hannah et al., 2008). Hyporheic exchange should be expected in coarse, highly permeable gravel-bed rivers such as the Girnock Burn (e.g. Malcolm et al., 2003). Hyporheic exchange is not considered to have been a major control on the longitudinal patterns observed in this study since (1) downstream longitudinal gradients observed at night were very small (i.e. $<0.5$ $\left.{ }^{\circ} \mathrm{C}\right)$ compared to daytime, (2) there was no consistent overprediction of water temperature during daylight hours and (3) bed heat flux was minimal at the three sites at which it was measured. However, it is possible that model errors were due to the poor representation of spatially heterogeneous hyporheic exchange, providing that hyporheic residence times were sufficient to alter the temperature of re-emerging hyporheic water relative to surface water. Improved representation of hyporheic exchange processes would involve quantifying (1) exchange rates and volumes, (2) residence times, (3) flowpath length and depth, and (4) temperatures of upand downwelling hyporheic water throughout the reach. To do this accurately and represent all flow paths would be an extremely significant challenge, and efforts to date have involved a large number of assumptions that could negate the value of estimates of this flux (e.g. Leach and Moore, 2014). Nevertheless, iterative advances in hyporheic understanding could progressively improve the predictive power of spatially distributed water temperature models, especially in the representation of daily temperature variability and lags, depending on the dominant hyporheic zone processes. 
Parameters were used in calculations of net radiation and turbulent fluxes. A sensitivity analysis was conducted on the threshold value used to convert hemispherical photographs into binary images for radiation modelling; this was possible because measurements of incident shortwave radiation were available to identify representative bounds for this value. Further parameters used for net radiation modelling were the emissivity of the water, riparian canopy and the atmosphere. Emissivity of the riparian canopy and the water were assumed to be equivalent to values identified during model calibration by Leach and Moore (2010) and used also by Moore et al. (2005) and MacDonald et al. (2014a, b) for riparian forest dominated by coniferous trees. Under overcast conditions, the emissivity of the atmosphere for net radiation modelling was dependent on cloud cover, for which observational data were unavailable. An average value for common cloud types (i.e. altostratus, altocumulus, stratocumulus, stratus and cumulus) was assumed (after Leach and Moore, 2010) but may not have been representative of actual cloud cover conditions. Net radiation model performance was good in comparison to previous applications (e.g. Leach and Moore, 2010), although we acknowledge further consideration could be given to the use of emissivity values derived for forest composed of different vegetation species and for potentially different meteorological conditions. Turbulent energy exchanges were calculated from micrometeorological measurements using commonly used methods (e.g. Webb and Zhang, 1997; Hannah et al., 2004, 2008; Leach and Moore, 2010, 2014; MacDonald et al., 2014c; Garner et al., 2014a); these equations are semiempirical (Ouellet et al., 2014) and thus do contain parameters, but they are not sitespecific. A sensitivity analysis was not performed on these parameters because, in the absence of direct measurements of latent and sensible heat (e.g. Guenther et al., 2012; Maheu et al., 2014), there was no basis for doing so. Nevertheless, it would have been beneficial to understand the effects of these parameters on model performance, and future studies may wish to address this.

Lastly, the flow routing and water temperature modelling assumed that no significant net gains or losses of stream flow occurred and that velocities were uniform throughout the reach. These assumptions were upheld at locations where flow accretion surveys (plus previous hydrochemical surveys; Malcolm et al., 2005) and concurrent velocity measurements were made (i.e. at $200 \mathrm{~m}$ intervals throughout the reach). Nevertheless, unidentified losses and gains to flow could have occurred within the uncertainties of the gauging approach, and water could have travelled at variable velocities between these survey locations depending on local channel characteristics. Consequently, it is possible that discharge and hydraulic retention time within parts of the reach could have been either increased or reduced, thus allowing enhanced or reduced rates of energy exchange. The good model performance observed herein suggests that the available data were broadly representative of conditions through- out the reach. However, the effects of net flow gains and losses and variable hydraulic retention times warrants further investigation in future studies.

\section{Conclusions}

The findings of this study have a number of important implications for researchers and river managers who may wish to assess the potential for mitigating water temperature extremes using riparian shading (e.g. riparian planting strategies). Our key finding is that water does not cool as it flows downstream under a semi-natural forest canopy. Instead, energy gains to the water column are reduced dramatically in comparison to open land use, which reduces the rate at which water temperature increases as it travels downstream. Thus, observed temperatures are controlled by a combination of lagged temperatures from upstream open reaches and lower rates of temperature increase within the forest. For reaches such as the Girnock Burn, where upstream land use does not shade the channel, instantaneous longitudinal cooling gradients are generated when the temperature of water advected into the reach increases over the day, while temperature increases are minimal for the water flowing beneath the forest canopy. This study was conducted under a "worst case scenario" of low flows and high energy gains; thus, under these extreme conditions, cooler stream refugia are anticipated to be present under forest canopies during daylight hours, but warming of the water column upstream of the forest will also control absolute water temperatures. Therefore, shading headwater reaches, where water is not in dynamic equilibrium with the atmosphere (e.g. Edinger et al., 1968; Hrachowitz et al., 2010; Kelleher et al., 2012; Garner et al., $2014 \mathrm{~b}$ ) and is thus cooler than the majority of locations lower in the basin (Poole and Berman, 2001), is anticipated to provide cool-water refugia for temperature-sensitive species and reduce temperatures further downstream.

Under future climates, surface energy balances are anticipated to change (Wild et al., 1997; Andrews et al., 2008) and discharge in catchments such as the Girnock, which have limited storage and shorter groundwater residence times, is anticipated to be more variable/extreme (Cappel et al., 2013). The water temperature modelling approach used in this study allows researchers and stream managers to explore the effects of variable prevailing weather and hydraulic conditions on stream temperatures and to identify optimal locations for the generation of cooling gradients under different shading regimes under present and future climates. Future research should utilise tools such as those presented herein to understand the effects of climate, hydraulic conditions, channel orientation and shading scenarios on water temperature. 
Author contributions. I. A. Malcolm, G. Garner and D. M. Hannah designed the study. G. Garner collected field data, wrote the flow routing model and the water temperature model scripts, and performed the simulations. G. Garner prepared the manuscript with input from I. A. Malcolm, J. P. Sadler and D. M. Hannah.

Acknowledgements. Grace Garner was funded by UK Natural Environment Research Council studentship NE/1528226/1. Anne Anckorn is thanked for cartographic assistance. Jason Leach and Dan Moore are thanked for generously sharing their net radiation model script. Nigel Mottram is thanked for his advice on the water temperature model script. Marine Scotland Science Freshwater Laboratory staff provided field and technical assistance and maintained and downloaded weather stations. SEPA provided discharge data. $\mathrm{R}$ was used for modelling and graphics. Martijn Westhoff, two anonymous reviewers and Hannah Cloke are thanked for comments that improved the manuscript.

Edited by: H. Cloke

\section{References}

Andrews, T., Forster, P. M., and Gregory, J. M.: A surface energy perspective on climate change, J. Climate, 22, 2557-2570, 2008.

Bartholow, J. M.: The Stream Segment and Stream network Temperature Models: A Self-Study Course, US Dept. of the Interior, Open-File Report 99-112, US Geological Survey, Fort Collins, CO, USA, 2000.

Beechie, T., Imaki, H., Greene, J., Wade, A., Wu, H., Pess, G., Roni, P., Kimball, J., Stanford, J., Kiffney, P., and Mantua, N.: Restoring salmon habitat for a changing climate, River Res. Appl., 29, 939-960, 2013.

Benyahya, L., Caissie, D., El-Jabi, N., and Satich, M. G.: Comparison of microclimate vs. remote meteorological data and results applied to a water temperature model (Miramichi River, Canada), J. Hydrol., 380, 247-259, 2010.

Beschta, R. L. and Taylor R. L.: Stream temperature increases and land use in a forested Oregon watershed, Water Resour. Bull., 24, 19-25, 1988.

Boyd, M. and Kasper, B.: Analytical methods for dynamic open channel heat and mass transfer: Methodology for heat source model Version 7.0, Oregon Department of Environmental Quality, Portland, OR, USA, 2003.

Brown, G. W., Swank, G. W., and Rothacher, J.: Water temperature in the Steamboat Drainage, USDA For. Serv. Res. Pap. PNW119, USDA, 1971.

Brown, L. E., Cooper, L., Holden, J., and Ramchunder, S. J.: A comparison of stream water temperature regimes from open and afforested moorland, Yorkshire Dales, northern England, Hydrol. Process., 24, 3206-3218, 2010.

Burnham, K. P. and Anderson, D. R.: Model Selection and Multimodel Inference: A Practical Information-Theoretic Approach, Springer, New York, NY, USA, 49-96, 2002.

Caissie, D.: The thermal regime of rivers: a review, Freshwater Biol., 51, 1389-1406, 2006.

Cappel, R., Tetzlaff, D., and Soulsby, C.: Will catchment characteristics moderate the projected effects of climate change on flow regimes in the Scottish Highlands?, Hydrol. Process., 27, 687699, 2013.

Danehy, R. J., Colson, C. G., Parrett, K. B., and Duke, S. D.: Patterns and sources of thermal heterogeneity in small mountain streams within a forested setting, Forest Ecol. Manage., 208, 287-302, 2005.

Edinger, J. E., Duttweiler, D. W., and Geyer, J. C.: The response of water temperatures to meteorological conditions, Water Resour. Res., 4, 1137-1143, 1968.

Evans, E. C., McGregor, G. R., and Petts, G. E.: River energy budgets with special reference to riverbed processes, Hydrol. Process., 12, 575-595, 1998.

Frazer, G. W., Canham, C. D., and Lertzman, K. P.: Gap Light Analyser (GLA), Version 2: Imaging Software to Extract Canopy Structure and Light Transmission Indices from True-Colour Fisheye Photographs, User's Manual and Program Documentation, Simon Fraser University and the Institute of Ecosystem Studies, Millbrook, NY, 1-38, 1999.

Garner, G., Malcolm, I. A., Sadler, J. P., Millar, C. P., and Hannah, D. M.: Inter-annual variability in the effects of riparian woodland on micro-climate, energy exchanges and water temperature of an upland Scottish stream, Hydrol. Process., doi:10.1002/hyp.10223, in press, 2014a.

Garner, G., Hannah, D. M., Sadler, J. P., and Orr, H. G.: River temperature regimes of England and Wales: spatial patterns, interannual variability and climatic sensitivity, Hydrol. Process., 28, 5583-5598, doi:10.1002/hyp.9992, 2014b.

Gomi, T., Moore, R. D., and Dhakal, A. S.: Headwater stream temperature response to clear-cut harvesting with different riparian treatments coastal British Columbia Canada, Water Resour. Res., 42, W08437, doi:10.1029/2005WR004162, 2006.

Guenther, S. M., Moore, R. D., and Gomi, T.: Riparian microclimate and evaporation from a coastal headwater stream, and their response to partial-retention forest harvesting, Agr. Forest Meteorol., 161, 1-9, 2012.

Hannah, D. M., Malcolm, I. A., Soulsby, C., and Youngson, A. F.: Heat exchanges and temperatures within a salmon spawning stream in the Cairngorms, Scotland: seasonal and sub-seasonal dynamics, River Res. Appl., 22, 919-940, 2004.

Hannah, D. M., Malcolm, I. A., Soulsby, C., and Youngson, A. F.: A comparison of forest and moorland stream microclimate, heat exchanges and thermal dynamics, Hydrol. Process., 22, 919-940, 2008.

Hannah, D. M., Malcolm, I. A., and Bradley, C.: Seasonal hyporheic temperature dynamics over riffle bedforms, Hydrol. Process., 15, 2178-2194, 2009.

Hastie, T. J. and Tibshirani, R. J.: Generalized additive models, Stat. Science, 1, 297-318, 1986.

Hrachowitz, M., Soulsby, C., Imholt, C., Malcolm, I. A., and Tetzlaff, D.: Thermal regimes in a large upland salmon river: a simple model to identify the influence of landscape controls and climate change on maximum temperatures, Hydrol. Process., 24, 3374-3391, 2010.

Imholt, C., Gibbins, C. N., Malcolm, I. A., Langan, S., and Soulsby, C.: Influence of riparian tree cover on stream temperatures and the growth of the mayfly Baetis rhodani in an upland stream, Aquat. Ecol., 44, 669-678, 2010.

Imholt, C., Soulsby, C., Malcolm, I. A., and Gibbins, C. N.: Influence of contrasting riparian forest cover on stream temperature 
dynamics in salmonid spawning and nursery streams, Ecohydrology, 6, 380-392, doi:10.1002/eco.1291, 2012.

Iqbal, M.: An Introduction to Solar Radiation, Academic Press, Toronto, 1-28, 1983.

Johnson, S. L. and Jones, J. A.: Stream temperature responses to forest harvest and debris flows in Western Cascades Oregon, Can. J. Fish. Aquat. Sci., 57, 30-39, 2000.

Keith, R. M., Bjornn, T. C., Meehan, W. R., Hetrickm, J., and Brusvenn, M. A.: Response of juvenile salmonids to riparian and instream cover modifications in small streams flowing through second-growth forests of south-east Alaska, T. Am. Fish. Soc., 127, 899-907, 1998.

Kelleher, C., Wagener, T., Gooseff, M., McGlynn, B., McGuire, K., and Marshall, L.: Investigating controls on the thermal sensitivity of Pennsylvania streams, Hydrol. Process., 26, 771-785, 2012.

Leach, J. A. and Moore, R. D.: Above-stream microclimate and stream surface energy exchanges in a wildfire distributed zone, Hydrol. Process., 24, 2369-2381, 2010.

Leach, J. A. and Moore, R. D.: Stream temperature dynamics in two hydrogeomorphically distinct reaches, Hydrol. Process., 25, 679-690, 2011.

Leach, J. A. and Moore, R. D.: Winter stream temperature in the rain-on-snow zone of the Pacific Northwest: influences of hillslope runoff and transient snow cover, Hydrol. Earth Syst. Sci., 18, 819-838, doi:10.5194/hess-18-819-2014, 2014.

Leach, J. A., Moore, R. D., Hinch, S. G., and Gomi, T.: Estimation of logging-induced stream temperature changes and bioenergetic consequences for cutthroat trout in a coastal stream in British Columbia, Canada, Aquat. Sci., 74, 427-441, 2012.

Macdonald, J. S., MacIsaac, E. A., and Heurer, H. E.: The effect of variable retention riparian buffer zones on water temperatures in small headwater streams in sub-boreal forest ecosystems of British Columbia, Can. J. Forest Res., 33, 303-316, 2003.

MacDonald, R. J., Boon, S., Byrne, J. M., Robinson, M. D., and Rasmussen, J. B.: Potential future climate effects on mountain hydrology, stream temperature and native salmon history, Can. J. Fish. Aquat. Sci., 71, 189-202, 2014a.

MacDonald, R. J., Boon, S., Byrne, J. M., and Silins, U.: A processbased stream temperature modelling approach for mountain regions, J. Hydrol, 511, 920-931, 2014b.

MacDonald, R. J., Boon, S., Byrne, J. M., and Silins, U.: A comparison of surface and subsurface controls on summer temperature in a headwater stream, Hydrol. Process., 28, 2338-2347, 2014c.

Maheu, A., Caissie, D., St-Hilaire, A., and El-Jabi, N.: River evaporation and corresponding heat flux in forested catchments, Hydrol. Process., 28, 5725-5738, 2014.

Malcolm, I. A., Youngson, A. F., and Soulsby, C.: Survival of salmonid eggs in a degraded in a degraded gravel-bed stream: effects of groundwater-surface water interactions, River Res. Appl., 19, 303-316, 2003.

Malcolm, I. A., Hannah, D. M., Donaghy, M. J., Soulsby, C., and Youngson, A. F.: The influence of riparian woodland on the spatial and temporal variability of stream water temperatures in an upland salmon stream, Hydrol. Earth Syst. Sci., 8, 449-459, doi:10.5194/hess-8-449-2004, 2004.

Malcolm, I. A., Soulsby, C., Youngson, A. F., and Hannah, D. M.: Catchment scale controls on groundwater-surfacewater interactions in the hyporheic zone: implications for salmon embryo survival, River Res. Appl., 21, 977-989, 2005.
Malcolm, I. A., Soulsby, C., Hannah, D. M., Bacon, P. J., Youngson, A. F., and Tetzlaff, D.: The influence of riparian woodland on stream temperatures: implications for the performance of juvenile salmonids, Hydrol. Process., 22, 968-979, 2008.

McGurk, B. J.: Predicting stream temperature after riparian vegetation removal, in: Proceedings of the Californian Riparian Systems Conference: Protection, Management and Restoration for the 1990s, 22-24 September 1989, Davis, California, 1989.

Moore, R. D., Sutherland, P., Gomi, T., and Dakal, A.: Thermal regime of a headwater stream within a clear-cut, coastal British Columbia, Hydrol. Process., 19, 2591-2608, 2005.

Ouellet, V., Secretan, Y., St-Hilaire, A., and Morin, J.: Water temperature modelling in a controlled environment: comparative study of heat budget equations, Hydrol. Process., 28, 279-292, 2014.

Poole, G. C. and Berman, C. H.: An ecological perspective on in-stream temperature : natural heat dynamics and mechanisms human-caused thermal degradation, Environ. Manage., 27, 787802, 2001.

Prata, A. J.: A new long-wave formula for estimating downward clear-sky radiation at the surface, Q. J. Roy. Meteorol. Soc., 122, 1127-1151, 1996.

R Core Team, R: A Language and Environment for Statistical Computing, R Foundation for Statistical Computing, Vienna, Austria, http://www.R-project.org, last access: 25 September 2013.

Roth, T. R., Westhoff, M. C., Huwald, H., Huff, J. A., Rubin, J. F., Barrenetxea, G., Vetterli, G., Parriaux, A., Selker, J. S., and Parlange, M. B.: Stream temperature response to three riparian planting scenarios by use of a distributed temperature validated model, Environ. Sci. Technol., 44, 2072-2078, 2010.

Rutherford, J. C., Blackett, S., Blackett, C., Saito, L., and DaviesColley, R. K.: Predicting the effects of shade on water temperature in small streams, New Zeal, J. Mar. Fresh., 31, 707-721, 1997.

Rutherford, J. C., Marsh, N. A., Davies, P. M., and Bunn, S. E.: Effects of patchy shade on stream water temperature: how quickly do small streams heat and cool?, Mar. Freshwater Res., 55, 737748, 2004.

Soetaert, K. and Petzoldt, T., Woodrow Setzer, R.: Solving Differential Equations in R: Package deSolve, J. Stat. Softw., 33, 1-25, 2010.

Story, A., Moore, R. D., and MacDonald, J. S.: Stream temperatures in two shaded reaches below cutblocks and logging roads: downstream cooling linked to subsurface hydrology, Can. J. Forest Res., 33, 1383-1396, 2003.

Tetzlaff, D., Soulsby, C., Gibbins, C., Bacon, P. J., and Youngson, A. F.: An approach to assessing hydrological influences on feeding opportunities of juvenile Atlantic salmon (Salmo salar): a case study of two contrasting years in a small, nursery stream, Hydrobiologia, 549, 65-77, 2005.

Tetzlaff, D., Soulsby, C., Waldron, S., Malcolm, I. A., Bacon, P. J., Dunn, S. M., Lilly, A., and Youngson, A. F.: Conceptualisation of runoff processes using a geographical information system and tracers in a nested mesoscale catchment, Hydrol. Process., 21, 1289-1307, 2007.

Torgerson, C. E., Price, D. M., Li, H. W., and McIntosh, B. A.: Multiscale thermal refugia and stream habitat associations of chinook salmon in northeastern Oregon, Ecol. Appl., 9, 301-319, 1999. 
Upper Dee riparian scheme, The River Dee Trust: http:// www.theriverdeetrust.org.uk/information/ourwork.asp (last access: 24 April 2014), 2011.

van Vliet, M. T. H., Ludwig, F., Zwolsman, J. J. G., Weedon, G. P., and Kabat, P.: Global river temperatures and sensitivity to atmospheric warming and changes in river flow, Water Resour. Res., 47, W02544, doi:10.1029/2010WR009198, 2011.

Webb, B. W. and Zhang, Y.: Spatial and seasonal variability in the components of the river heat budget, Hydrol. Process., 11, 79$101,1997$.

Webb, B. W., Hannah, D. M., Moore, R. D., Brown, L. E., and Nobilis, F.: Recent advances in stream and river temperature research, Hydrol. Process., 22, 902-918, 2008.

Westhoff, M. C., Savenije, H. H. G., Luxemburg, W. M. G., Stelling, G. S., van de Giessen, N. C., Selker, J. S., Pfister, L., and Uhlenbrook, S.: A distributed stream temperature model using high resolution temperature observations, 4, 1469-1480, 2007.

Westhoff, M. C., Bogaard, T. A., and Savenije, H. H. G.: Quantifying the effect of in-stream rock clasts on the retardation of heat along a stream, Adv. Water Resour., 11, 1417-1425, 2010.
Westhoff, M. C., Bogaard, T. A., and Savenije, H. H. G.: Quantifying spatial and temporal discharge dynamics of an event in a first order stream, using distributed temperature sensing, Hydrol. Earth Syst. Sci., 15, 1945-1957, doi:10.5194/hess-15-19452011, 2011.

Wilby, R. L., Orr, H. G., Watts, G., Battarbee, R. W., Berry, P. M., Chadd, R., Dugdale, S. J., Dunbar, M. J., Elliott, J. A., Extence, C., Hannah, D. M., Holmes, N., Johnson, A. C., Knights, B., Milner, N. J., Ormerod, S. J., Solomon, D., Timlett, R., Whitehead, J., and Wood, P. J.: Evidence needed to manage freshwater ecosystems in a changing climate: turning adaptation principles into practice, Sci. Total Environ., 408, 4150-4164, 2010.

Wild, M., Ohmura, A., and Cubasch, U.: GCM-simulated energy fluxes in climate change experiments, J. Climate, 10, 3093-3110, 1997.

Wood, S. N.: Generalized additive models: an introduction with R, Boca Raton, Chapman and Hall/CRC, Boca Raton, 1-391, 2006.

Zwieniecki, M. and Newton, M.: Influence of streamside cover and stream features on temperature trends in forested streams of western Oregon, West. J. Appl. For., 14, 106-112, 1999. 